Yao, C.; Darby, C.; Hurlebaus, S.; Price, Gerald R.; Sharma, H.; Hunt, Beatrice E.; Yu, O.-Y.; Chang, Kuang-An; Briaud, Jean-Louis

\title{
Scour Monitoring Development for Two Bridges in Texas
}

Verfügbar unter / Available at:

https://hdl.handle.net/20.500.11970/100264

Vorgeschlagene Zitierweise / Suggested citation:

Yao, C.; Darby, C.; Hurlebaus, S.; Price, Gerald R.; Sharma, H.; Hunt, Beatrice E.; Yu, O.-Y.; Chang, Kuang-An; Briaud, Jean-Louis (2010): Scour Monitoring Development for Two Bridges in Texas. In: Burns, Susan E.; Bhatia, Shobha K.; Avila, Catherine M. C.; Hunt, Beatrice E. (Hg.): Proceedings 5th International Conference on Scour and Erosion (ICSE-5), November 7-10, 2010, San Francisco, USA. Reston, Va.: American Society of Civil Engineers. S. 958-967. 


\title{
Scour Monitoring Development for Two Bridges in Texas
}

\author{
C. Yao ${ }^{1}$, C. Darby ${ }^{1}$, S. Hurlebaus ${ }^{1}$, G. R. Price ${ }^{2}$, H. Sharma ${ }^{1}$, B. E. Hunt ${ }^{3}$, O.-Y. Yu ${ }^{1}$, \\ K.-A. Chang ${ }^{1}$, J.-L. Briaud ${ }^{1}$
}

${ }^{1}$ Zachry Department of Civil Engineering, Texas A\&M University, College Station, Texas 77843-3136, USA, Corresponding Email: congpu.vaoragmail.com, ibriaud@icivil.tamu.edu

${ }^{2}$ ETI, 1317 Webster Ave., Ft. Collins CO 80524

${ }^{3}$ STV, Incorporated, 225 Park Ave. S, New York NY 10003-1604

\begin{abstract}
Bridge scour monitoring using fixed instrumentation is a good way for the owner to be warned of imminent failure and to take appropriate action before exposing the public to undue risk. This paper demonstrates two cases of bridge scour monitoring systems developed for two bridges in Texas. The lessons learned from the two systems lead the authors to the conclusion that Tethered Buried Switches for early warning and tilt sensors for warning system should be preferred. Acceleration and frequency-based behavior tracked by motion sensors show promise but could only be demonstrated in laboratory experiments, with insufficient field data.
\end{abstract}

\section{INTRODUCTION}

According to a recent study (Hunt, 2009), 58\% of bridge failures result from scour, making scour monitoring a significant issue in civil engineering. Scour monitoring using fixed instrumentation is an effective method to predict the imminent failure of a bridge. The focus of this paper is to show some development in scour monitoring based on instruments, including motion sensor, tilt sensor, float-out device, water stage sensor, sonar sensor, and Tethered Buried Switch (TBS) instrument installed on two bridges in Texas.

\section{DEVICES FOR SCOUR MONITORING}

\section{Motion sensor}

The motion sensor measures the acceleration response of the bridge in three directions. In our project, it recorded the acceleration in three directions at rates of 80 $\mathrm{Hz}$ (field experiment) and $124 \mathrm{~Hz}$ (laboratory experiment).

The Japan Railway Technical Research Institute (RTRI) published a study in 2008 (Shinoda et al. 2008), which provides a new method to evaluate the stiffness of a railway bridge column called the Impact Vibration Method. The authors showed that the natural frequency of the column decreases when the stiffness of the bridge column and its foundation decrease. Thus the integrity of the column could be judged by comparing the natural frequency measured when it is known that the foundation is in good order with the natural frequency during a big flood. Inspired by this idea, we are considering using a motion sensor to monitor scour sensitive bridge columns.

Other Japanese researchers (Suzuki et al. 2007) conducted research on the health monitoring of railway bridge piers, and found that the gradient of linear 
regression line between vertical and transverse acceleration response changed due to the loss of sediment support around the bridge foundation. Therefore this technique is also tried in this paper by using the ratio of the Root Mean Square (RMS) of the acceleration in two directions.

\section{TBS}

The TBS (Figure 1) is a float-out device which is hardwired to the data acquisition system. It was invented during this project by ETI Instrument Systems, Inc. The TBS consists of a hollow aluminum rod containing an electrical switch which triggers when the rod is horizontal or near horizontal. The wire has advantages and disadvantages, as it might be cut by debris, but can allow the user to address the sensor and provide power. Regular float-out devices are wireless but have a finite lifetime due to the battery. The aluminum rod of the TBS is rotated to horizontal by hydraulic drag rather than buoyancy. In the horizontal direction the sensor gives a warning signal.

\section{Other instruments}

Other instruments used in our project include tilt sensor, float-out device, water stage sensor, and sonar sensor. The tilt sensor measures the tilt of the structural member to which it is attached. It is easy to install, but it likely gives a warning after the TBS and the float-out devices have floated out. The float-out device (Figure 2) floats out when the scour hole reaches the depth where the float-out device is located; when it floats out it gives a signal indicating that this scour depth has been reached. It is not easy to install for a real bridge. To bury the float-out device near the bridge pier, a hole needs to be drilled through the deck into the soil to the required depth. The water stage sensor (Figure 3) is fixed to the bridge deck and measures the distance from the instrument to the water surface. The water stage sensor can also be designed to present the water surface elevation above the mean sea level given the elevation of the bridge deck where the water stage sensor is located. The sonar sensor measures the distance between the location of the head of the sensor and the soil surface it is aimed at. It only gives reliable readings when it is within the proper working range.

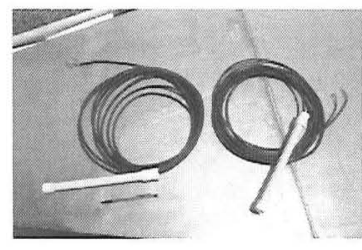

Figure 1. TBS

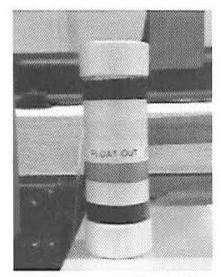

Figure 2. Float-out device

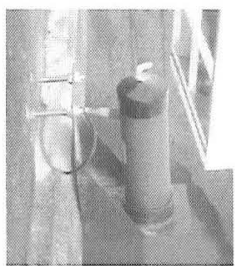

Figure 3. Water stage sensor

\section{LABORATORY EXPERIMENT}

In the laboratory experiment, the concrete column, $0.45 \mathrm{~m}$ in diameter and 4 $\mathrm{m}$ long, was embedded to a depth of $0.3 \mathrm{~m}$ in the sand, then two prefabricated 
concrete decks each $0.53 \mathrm{~m}$ wide, $2.03 \mathrm{~m}$ long, and $0.1 \mathrm{~m}$ thick were placed end-toend on top of the column to simulate a bridge with a shallow spread footing foundation in the 2D flume at Texas A\&M University. Motion sensor, tilt sensor, water stage sensor, sonar sensor and float-out device were used in the experiment. Figure 4 shows the illustration of the experiment setup.

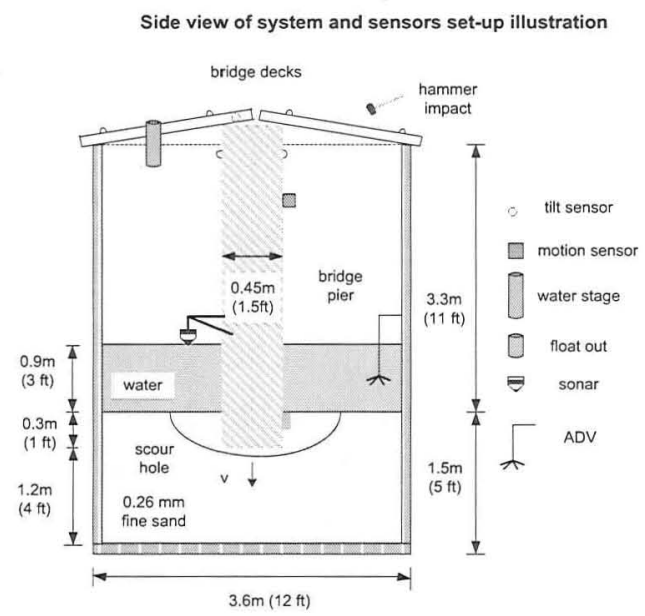

Figure 4. Experiment set-up illustration

The experiment lasted 6 hours and 45 minutes. First, the deck was struck with a $4.4 \mathrm{~N}$ rubber hammer. Then water was filled up to $0.9 \mathrm{~m}$ high in the flume, and a set of impact tests was implemented with a water velocity of $0.15 \mathrm{~m} / \mathrm{s}, 0.3 \mathrm{~m} / \mathrm{s}$, and $0.45 \mathrm{~m} / \mathrm{s}$. It took almost 20 minutes for the test under each flowing velocity. At 0.45 $\mathrm{m} / \mathrm{s}$ (3.6 hours) the scour hole started to develop. When the water velocity reached $0.6 \mathrm{~m} / \mathrm{s}$ ( 4.5 hours), the scour hole reached the foundation level, the foundation started to be undermined, the column began to settle, and the tilt sensor indicated a change in deck inclination.

Figure 5 shows the results of the data analysis in the time domain. To study the signal in the frequency domain in detail, the acceleration trace was broken into small time intervals based on the test procedure. Figure 6 shows the relationship between the first observed frequency of the system, the ratio of RMS values of the acceleration in two directions and the tilt angle in two directions. The figure indicates that the tilt sensor reported movement at 4.5 hours after the start when the scour hole became deep enough and the column started to settle. By comparison, the frequency vs. time plots gives earlier detection ( 3.5 hours after the start). The ratio of RMS values in flow direction and vertical direction changes dramatically at 4.5 hours, which is consistent with the tilt sensor readings. 

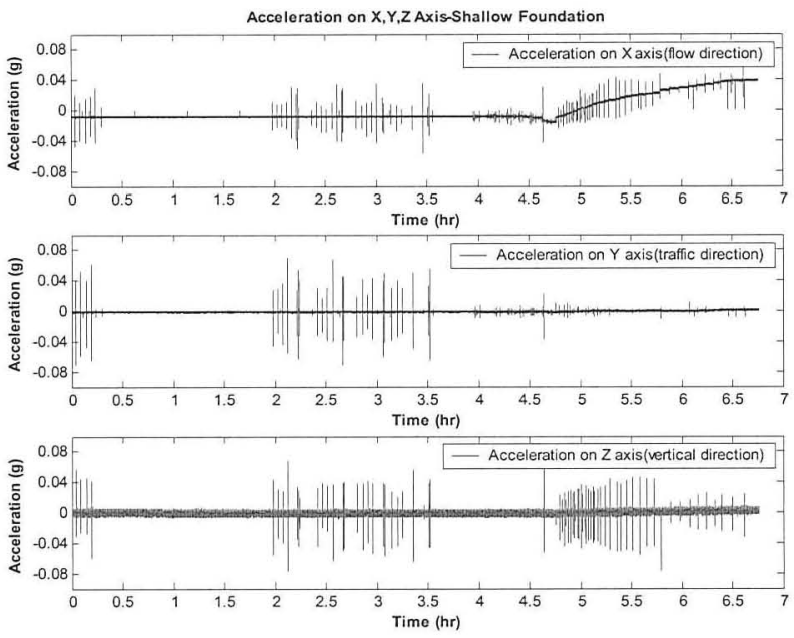

Figure 5. Acceleration in $X, Y, Z$ axis
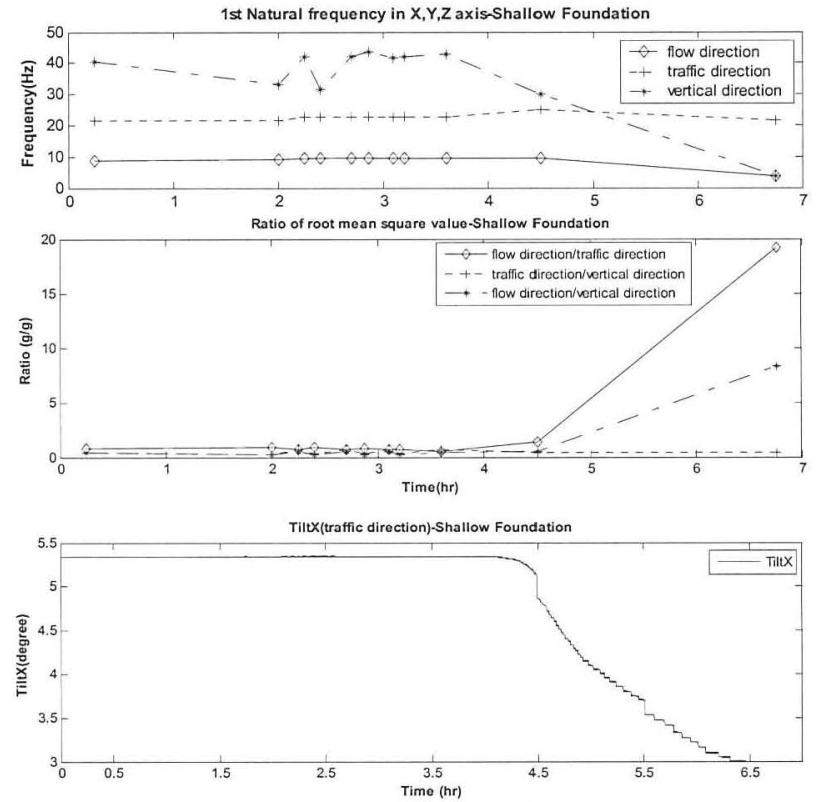

Figure 6. Comparison of frequency analysis, RMS analysis and tilt sensor reading 
This experiment shows that the RMS ratio method, the FFT analysis method and the tilt sensor data give comparable results. The scour hole creates a lower stiffness of the foundation which results in a decrease in natural frequency of the column. The ratio of two RMS values of the acceleration also changes when the bridge experiences scour. Both methods can theoretically be used as warning of bridge failure due to scour.

\section{US59 BRIDGE OVER GUADALUPE RIVER}

\section{Project background}

The Southbound bridge of US Highway 59 over the Guadalupe River, south of Victoria, Texas was chosen to be monitored because the Guadalupe River is both meander-prone and flood-prone, and a drilled shaft (Figure 7) on the north end of the bridge was exposed by a major flood in 1998. The main bridge is $111 \mathrm{~m}$ long with three spans. It includes two river piers constructed as web-walls on foundations made of H-piles to a depth of approximately $9 \mathrm{~m}$ below the pile cap which is about $1 \mathrm{~m}$ below the river bed. The soil varies significantly, with layers of all gradations from gravel to clay, tending toward silt and sand.

\section{Instrumentation}

The instruments include a wired and a wireless motion sensor on each cap beam of the piers in the river (SB1 and SB2 in Figure 8). They are located below the deck and glued to the cap beam. One tilt sensor was bolted to the side of the bridge rail to measure the tilt angle of the deck near SB2. One water stage sensor was fixed to the side of the bridge deck near the tilt sensor to measure the water elevation. Two float-out devices were placed at a depth of $0.6 \mathrm{~m}$ and $1.2 \mathrm{~m}$ below the pile cap respectively; they were installed at the bottom of a boring near one pile cap (SB2 on Figure 8). Two TBS instruments were placed $1.5 \mathrm{~m}$ and $4.5 \mathrm{~m}$ respectively below the ground surface near the south abutment; they were installed at the bottom of a boring near the abutment. A datalogger was secured on top of the capping beam of SB2 to collect data every twenty minutes and transmit the data by cellular modem to a remote server at Texas A\&M University.

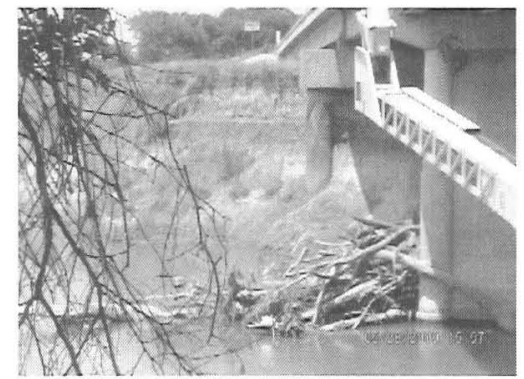

Figure 7. Exposed drill shaft

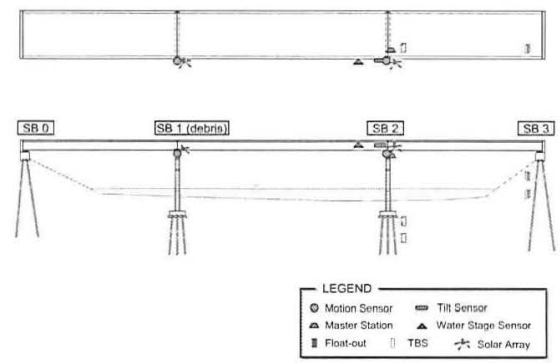

Figure 8. Schematics of instrument placement 


\section{Data analysis}

Figure 9 shows the tilt sensor reading from May 28, 2009 to Feb 19, 2010. The tilt sensor indicates that very little tilt occurred on this bridge during that period. Both TBS instruments gave a constant value of 1 indicating that they remained buried. Both float-out devices gave a constant value of 0 which means that the devices were working properly and had not floated out. The water stage sensor is measuring the water surface elevation above the mean sea level (Figure 10). We also used the water gage reading from USGS gage 08176500 to check our sensor. The data for that gage can be found on the web site listed in the references. This gage is located approximately $12 \mathrm{~km}$ upstream of the bridge. The comparison is shown in Figure 11 and indicates a good comparison when the stage sensor was working properly.
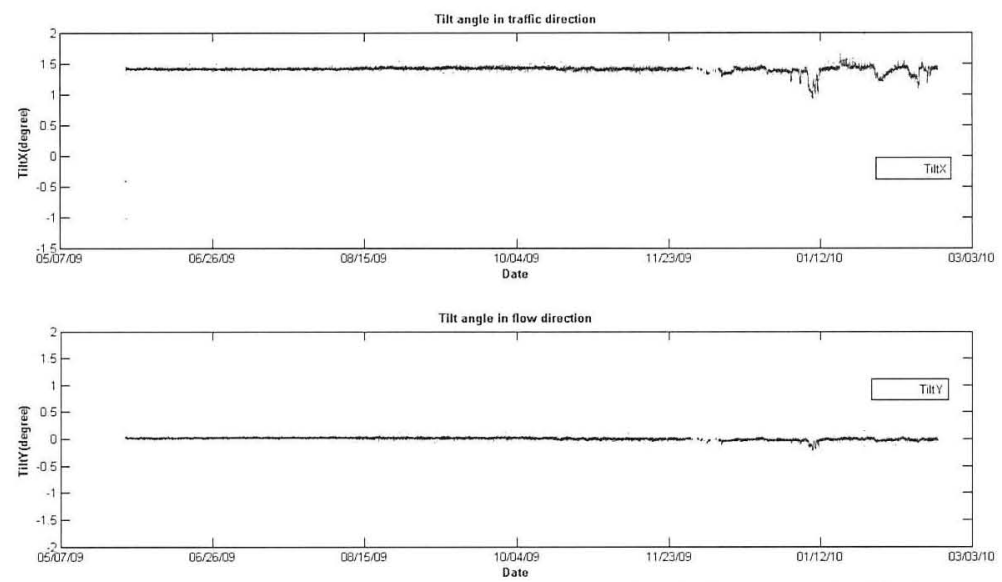

Figure 9. Tilt sensor reading from May 28, 2009 to Feb 19, 2010

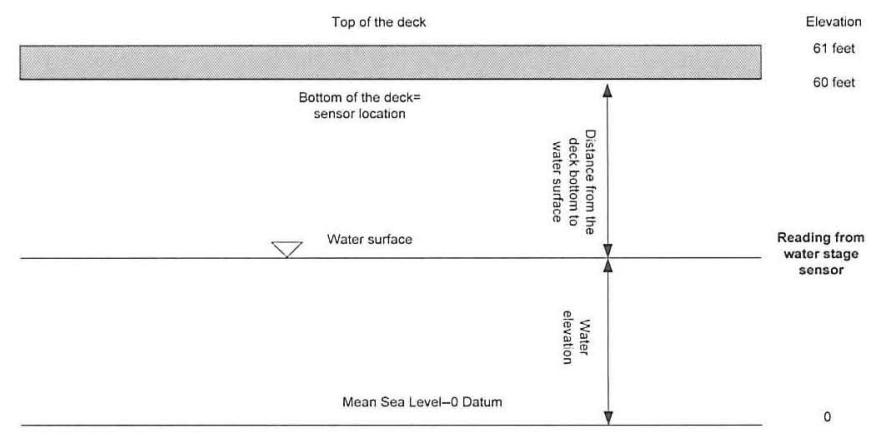

Figure 10. Description of measurement from water stage sensor 


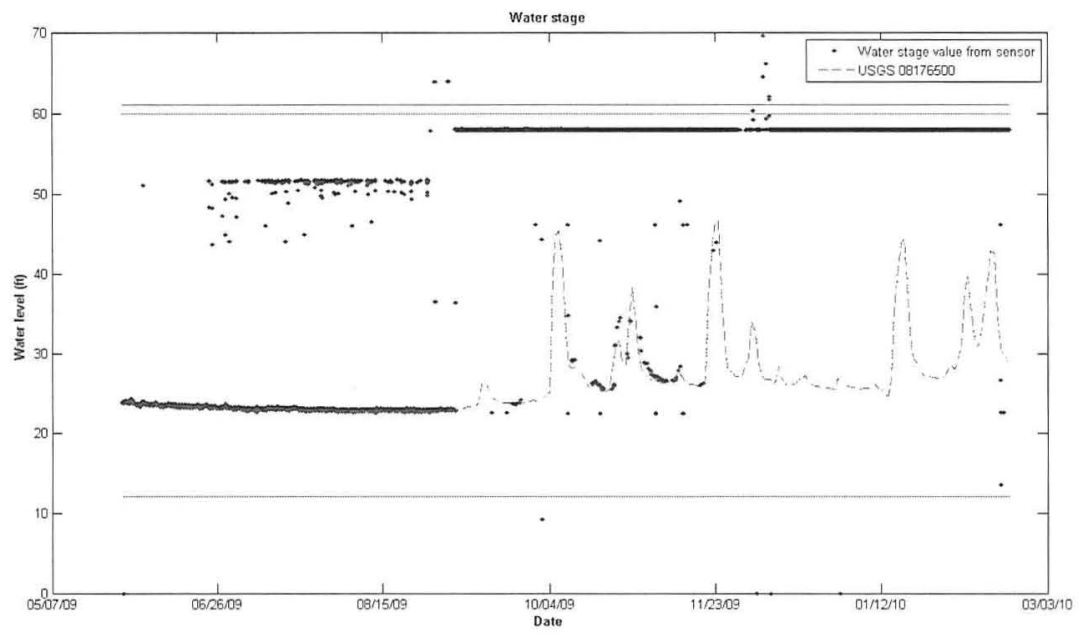

Figure 11. Water stage sensor reading from May 28, 2009 to Feb 19, 2010

A set of 148 groups of acceleration data obtained from the wireless motion sensor on US59 Bridge from June $2 @ 10: 00$ am to June 8, @ 13:00 pm were analyzed using the RMS method (Figure 12). As can be seen, a reasonable linear regression exists between each couple of values indicating that the ratio of the RMS values was constant during that week.
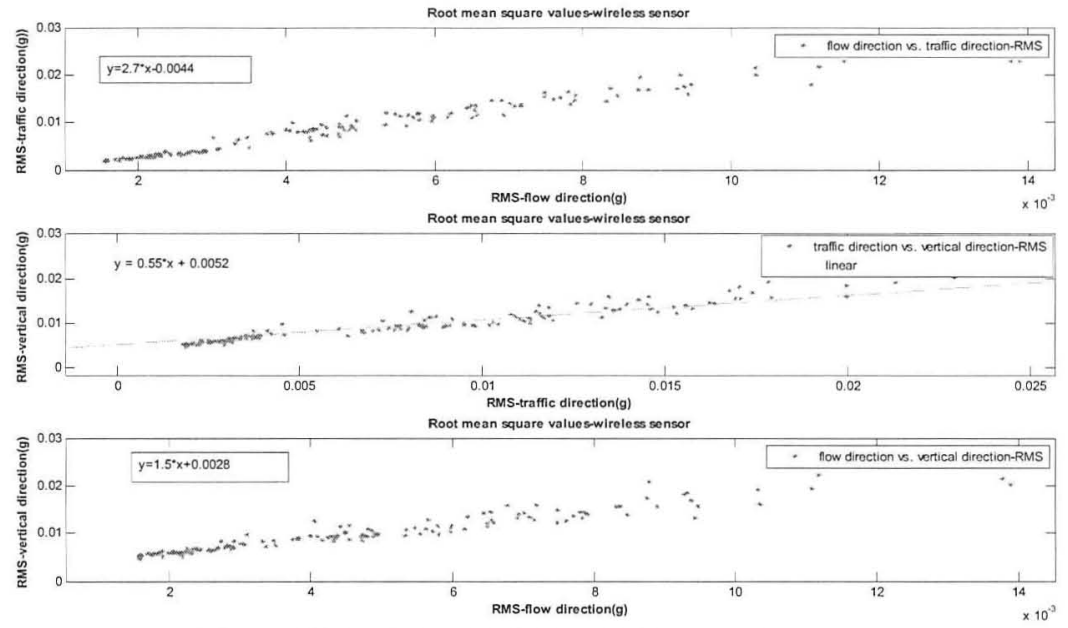

Figure 12. RMS analysis for wireless motion sensor 


\section{Discussion}

The system was installed on US59 over Guadalupe River on May 28, 2009. We lost connection on the motion sensors from June 8, 2009 to October 15, 2009 because of problem with the phone company. Further problems occurred when it was realized that the solar power units were under-powered. Because of their high sampling rate, motion sensors drew more power than any other sensor, and gave difficult-to-interpret data. The acceleration response to vehicle excitation could be seen clearly but once transformed in the frequency domain, the data was very noisy and one could not distinguish different mode shapes.

While the frequency domain analysis for these motion sensors did not give a clear natural frequency for the bridge, the ratio of the acceleration RMS values from the motion sensors is a promising, simple quantity to use as a warning indicator.

In summary, the tilt sensor, the flout-out devices, the TBS, and the master station worked well while the motion sensors and the water stage did not.

\section{SH80 BRIDGE AT SAN ANTONIO RIVER}

\section{Project background}

The bridge on State Highway 80 (Figure 13) at San Antonio River, near Karnes City, was selected for implementation. It was equipped with one wireless motion sensor, one hardwired motion sensor, and two TBS instruments for scour monitoring. The data was relayed by cellular modem to Texas A\&M University for data reduction.

\section{Instrumentation}

Two motion sensors were glued on the top of the center pier and the pier on the bank of the main channel respectively (Figure 13 and 14). TBS-1 and TBS2 were placed in a hand-augered borehole near the pier on the bank of the main channel. TBS1was buried $2.4 \mathrm{~m}$ below the ground surface and exactly $12.3 \mathrm{~m}$ below the top of the deck. TBS 2 was buried $1.5 \mathrm{~m}$ below the ground surface and exactly $11.4 \mathrm{~m}$ below the top of the deck. Figure 14 shows the location of the instruments for the SH80 bridge over San Antonio River.

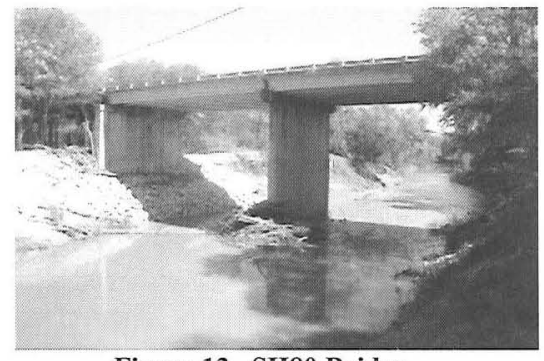

Figure 13. SH80 Bridge

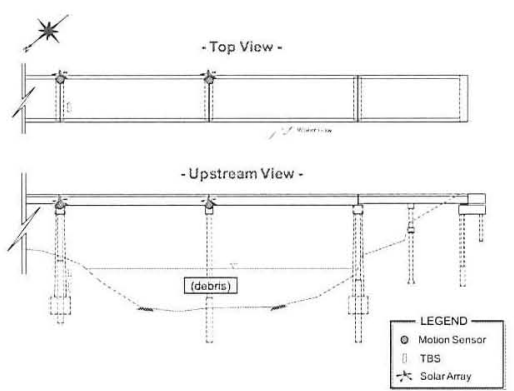

Figure 14. Schematics of instrument placement 


\section{Data analysis}

Figure 15 shows that the two TBS instruments gave a value of 1 which means that the sensors were working properly and had not scoured out. The gap in the two plots corresponds to the period when the power went down. The motion sensors on this bridge did not give useful data except in December 2009.

\section{Discussion}

The monitoring system was installed on SH80 at San Antonio River on Oct 16, 2009. The hardwired sensor gave clean data in December, 2009. The wireless sensor gave clean data on Oct 20,2009. The rest of the time the data was unsatisfactory. The motion sensors were therefore removed and replaced with tilt sensors on March 11, 2010. The TBS sensors gave clean data except for the period where there was no power.


Figure 15. TBS equipment reading from Oct 16, 2009 to Feb 21, 2010

\section{CONCLUSIONS AND SUGGESTIONS}

With respect to the motion sensors, the frequency domain analysis and the acceleration ratio approach require a lot of data to be collected and stored. Therefore motion sensors require a lot of power to acquire and transmit the data in the field. The two approaches (frequency and acceleration ratio) worked well for the "model bridge" in the laboratory experiment because the structure and its vibration were simple. The response to vibrations of full scale bridges is much more complex, requires controlled and large excitation for useful data to be collected. The frequency content of the response is complex and the acceleration ratios are not consistent. So motion sensors are a good idea for bridge scour monitoring but require much more work.

Tilt sensors are reliable, simple, and relative low cost instruments. They are recommended as integrating behavior sensors which work when failure approaches. They can be helpful for other than scour. 
Tethered Buried Switches are new and likely helpful, but relatively costly to install and cover only one location chosen by the engineer. They are recommended for early warning but in combination with tilt sensors. In comparison, float-out devices are likely helpful but not addressable and have limited battery life. They are recommended for short term warning systems.

\section{ACKNOWLEDGEMENT}

This project is sponsored by the Texas Department of Transportation. Marcus Galvan, John Delphia and Mark McClelland at TxDOT have been particularly helpful. We are also indebted to John Reed at Texas A\&M University for his help during the laboratory experiments. Thanks very much for the tremendous help from Jason Kurten, Deeyvid Saez and Stacey Tucker during the repair of the two bridge monitoring systems.

\section{REFERENCES}

Briaud, J.-L., Yao, C., Darby, C., Sharma, S., Hurlebaus, S., Price, G.R., Chang, K.A., Hunt, B.E., Yu, O.-Y. Motion Sensors for Scour Monitoring: Laboratory Experiments and Numerical Simulations. The Transportation Research Board (TRB) 89th Annual Meeting. Washington, D.C. January 10-14, 2010.

Darby, C., Yao, C., Hurlebaus, S., Price, J., Hunt, B.E., Yu, O.Y., Chang, K.-A., Briaud. J.L. Motion Sensors for Bridge Scour Monitoring: Preliminary Laboratory and Field Experience. Texas Section-ASCE fall 2009 meeting. The Woodlands, Texas. October 28-31, 2009.

Hunt, B. E. (2009) "Monitoring of Scour Critical Bridges." NCHRP Synthesis of Highway Practice 396, Transportation Research Board, Washington, D.C.

Suzuki, O., Abe, M., Shimamura, M., Matsunuma, M. A Health Monitoring System for Railway Bridge Piers. The 3rd International Conference on Structural Health Monitoring of Intelligent Infrastructure, Vancouver, British Columbia, Canada, November 13-16, 2007.

Shinoda, M, Haya, H., Murata, S. (2008) "Nondestructive Evaluation of Railway Bridge Substructures by Percussion Test." Fourth International Conference on Scour and Erosion (CD-ROM), Tokyo, Japan.

Yao, C., Darby, C., Yu, O.-Y., Hurlebaus, S., Chang, K.A., Price, J., Hunt, B., Briaud. J.-L. Motion Sensors for Scour Monitoring: Laboratory Experiment with a Shallow Foundation. Proceedings of GeoFlorida 2010, West Palm Beach, Florida. February 20-24, 2010. ASCE

http://waterdata.usgs.gov/tx/nwis/uv?site no $=08176500 \&$ format=gif\&period $=31$ 